\title{
A Peroxotungstate-Ionic Liquid Brush Assembly: an Efficient and Reusable Catalyst for Selectively Oxidizing Sulfides with Aqueous $\mathrm{H}_{2} \mathrm{O}_{2}$ Solution in Neat Water
}

\author{
Xianying Shi,*Wenjuan Ma, Hui Ou, Xiaoyan Han, Congmin Lu, Yan Chen and Junfa Wei* \\ School of Chemistry and Chemical Engineering, Shaanxi Normal University and Key Laboratory for \\ Macromolecular Science of Shaanxi Province, Xi'an, 710062, P. R. China
}

\begin{abstract}
Uma sistema catalítico heterogêneo de peroxotungstato realizado em líquido iônico (IL) tipo escova foi sintetizado e aplicado na oxidação seletiva de sulfetos a temperatura ambiente e usando peróxido de hidrogênio 30 wt. \% como oxidante terminal e água como solvente. Nenhum cosolvente orgânico ou outro aditivo foi necessário e a reação ocorre com uma quantidade de 1,5-2,0 mol\% (baseado no W) de catalisador. Sulfetos alifáticos e aromáticos foram transformados de maneira eficiente e seletiva em seus respectivos sulfóxidos ou sulfonas pelo controle dos equivalentes de peróxido de hidrogênio. Grupos funcionais sensíveis à oxidação, tais como ligações duplas e hidroxila, não foram afetados mesmo com excesso de peróxido de hidrogênio. O catalisador foi recuperado após a reação via filtração e reutilizado pelo menos oito vezes sem perda significativa de atividade.
\end{abstract}

An efficient and reusable heterogeneous catalytic assembly of peroxotungstate held in a ionic liquid (IL) brush was synthesized and an environmentally-friendly procedure was developed for selective oxidation of sulfides at room temperature using $30 \mathrm{wt}$ \% hydrogen peroxide as the terminal oxidant and water as a sole solvent. No organic co-solvent or other additive was needed. A 1.5-2.0 mol\% (based on W atom) loading catalyst was found to be sufficient for a smooth and clean reaction. Both aliphatic and aromatic sulfides were efficiently and selectively transformed into their respective sulfoxides or sulfones by simply controlling of equivalents of hydrogen peroxide. In addition to the high catalytic activity, the catalyst exhibits excellent chemoselectivity. Sensitive functional groups, such as double bond and hydroxyl, remained under the oxidation conditions the reaction even with an excess hydrogen peroxide. The catalyst was easily recovered (via simple filtration) and reused at least eight times without a noticeable loss of activity.

Keywords: green catalysis, ionic liquid brush, clean oxidation, hydrogen peroxide

\section{Introduction}

Sulfoxides and sulfones have interested organic chemists for a long time because of their importance as synthetic intermediates in $\mathrm{C}-\mathrm{C}$ bond formation and various molecular rearrangements. ${ }^{1-3}$ The oxidation of sulfides is a straightforward and frequently method used to obtain sulfoxides and sulfones. Among various oxidants employed in the reactions, ${ }^{4-14}$ hydrogen peroxide is an attractive and environmentally-friendly oxidant owing to its low cost, high availability and cleanliness. ${ }^{15-19}$ However, hydrogen peroxide alone exhibits a weak oxidative ability and a catalytic activation is required to access its full potential.

*e-mail: shixy@snnu.edu.cn, weijf@snnu.edu.cn
Tungsten based catalysts, especially peroxotungstates, have been observed to be efficient catalysts using hydrogen peroxide as the oxidant and heterogeneous peroxotungstate catalysts are of significant industrial interest since they can be easily separated and recycled. ${ }^{20,21}$ In 2008, our group reported the application of peroxotungstates immobilized on mono-layer ionic liquid-modified silica in the selective oxidation of sulfides. ${ }^{22}$ Although, these catalysts displayed excellent activities, the reactions can only take place well in the mixed solvent of $\mathrm{CH}_{3} \mathrm{OH}$ and $\mathrm{CH}_{2} \mathrm{Cl}_{2}$, which can bring about environmental pollution. In view of economic and environmental problems, the replacement of environmentally-friendly reaction medium to the organic solvent is important research topic to perform oxidation reaction. Water as a medium for organic reactions has attracted great attention due to its low cost and safety to 
industrial processes and to environment. ${ }^{23-26}$ Whereas water is still not commonly used as sole solvent in oxidation reaction because of its poor compatibility with organic substrates.

Our group has been involved in the development of green catalysts and environmentally-friendly procedures to organic transformations. Recently, it was synthesized a set of silica-supported multilayer ionic liquids (ILs) bearing two or more imidazolium ions on each of the side chains. ${ }^{27,28}$ They were called "ionic liquid brushes" because of their brush-like feature. In comparison with the monolayer ILs previously reported, it was expected that our immobilized multiple layer ILs should act as highly active catalysts on the basis of the following characteristics: (i) the brush extends the immobilized ILs to the upper spaces outside the surface of the supports, offering a deeper 3D environment that closely resembles the liquid-phase character of ionic liquids for both hydrophilic and hydrophobic reactants, (ii) more flexibility of the longer branched chains for more substrates and reagents to be accommodated and to access the catalytic species, and (iii) more catalytic species can be loaded on the unit surface by exchanging with anion of IL. Our group proved their high efficiency and recyclability for some organic reactions in neat water. ${ }^{27}$

Encouraged by our previous research, it was developed a catalytic assembly of dianion peroxotungstates held in bis-layer ionic liquid brushes-modified silica $\mathrm{SiO}_{2}$-BisILs $\left[\mathrm{W}_{2} \mathrm{O}_{3}\left(\mathrm{O}_{2}\right)_{4}\right]$ (Figure 1). It was envisioned that this catalytic assembly could work well as a green and reusable catalyst in on-water reactions using $\mathrm{H}_{2} \mathrm{O}_{2}$ as oxidant. More importantly, as a supported bi-positively charged organic salt, our bis-layer ionic liquid brush, bearing two imidazolium cations on each of its side chains, would tightly associate with the peroxotungstate dianions via a strong electrostatic interaction. Therefore, the loss of active components or the contamination of metal ions in the product should be significantly minimized or even eliminated. Herein, it is presented our studies on a peroxotungstate-in-brush catalytic assembly for the selective oxidation of sulfides to sulfoxides or sulfones in neat water under mild conditions.

\section{Results and Discussion}

The heterogeneous catalytic assembly was prepared by immobilizing the active peroxotungstate onto inorganic materials, $\mathrm{SiO}_{2}$ modified with the ionic liquid by ion exchange (Scheme 1). The results of elemental analysis, IR (infrared) spectra and SEM-EDAX (scanning electron microscopy-energy dispersive X-ray spectroscopy) studies of the catalyst and intermediates displayed that the ionic liquid anion $\mathrm{PF}_{6}^{-}$was not completely exchanged by the binuclear peroxotungstate anion $\left[\mathrm{W}_{2} \mathrm{O}_{3}\left(\mathrm{O}_{2}\right)_{4}\right]^{2-}$. Consequently, the feature of the homogeneous reaction of the ionic liquid was shifted to the heterogeneous catalyst. Meanwhile, the grafted ionic liquid avoids the disadvantage that a little loss in the homogeneous system would lead to an enhancement in cost.

The oxidation of methyl phenyl sulfide was selected as a prototypical reaction for the assessment of suitable reaction

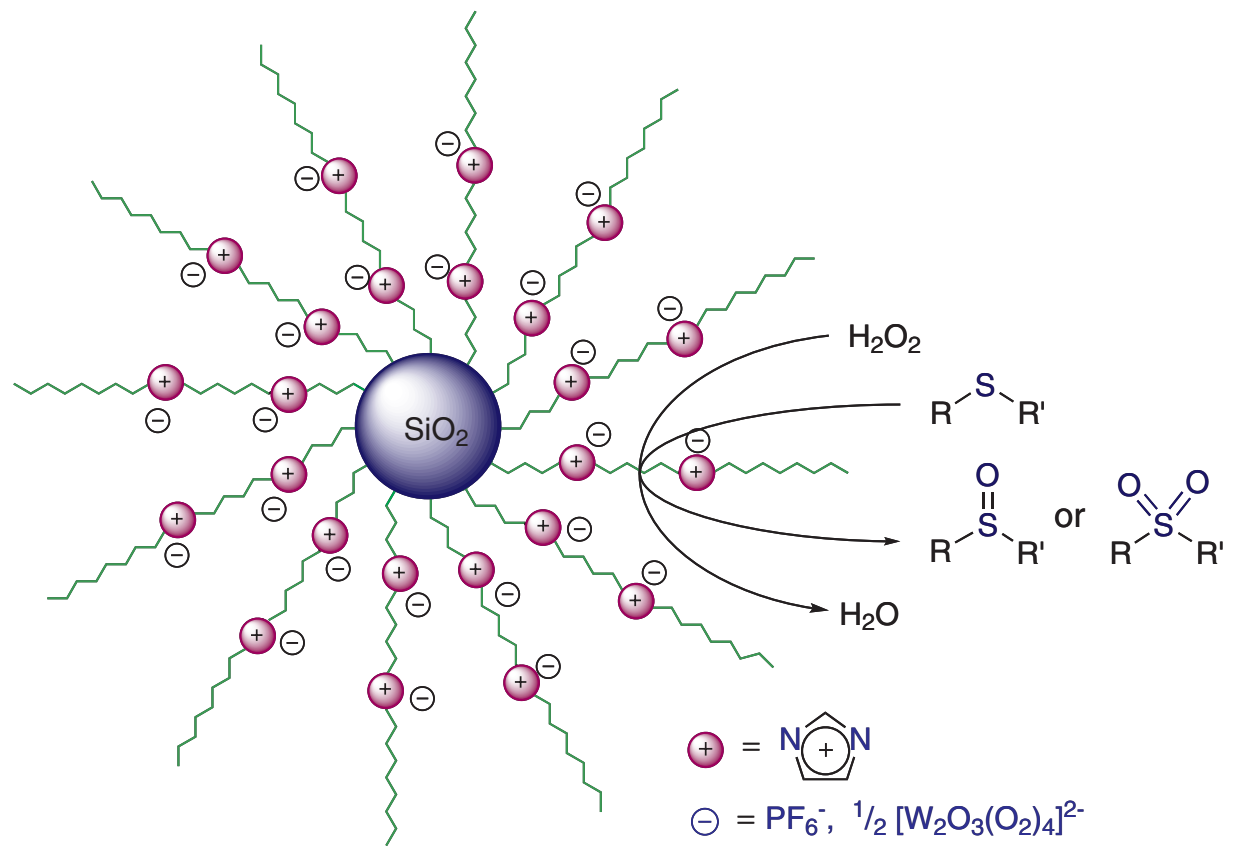

Figure 1. Peroxotungstate held in bislayer ionic liquid brushes and its role in the reaction. 
<smiles>CCCN1C=CN(CCCC[Si]2(OCC)Oc3cccc(O)c3O2)C=C1</smiles>

Ionic liquid brushes $\mathrm{SiO}_{2}$-BisILs[Cl]
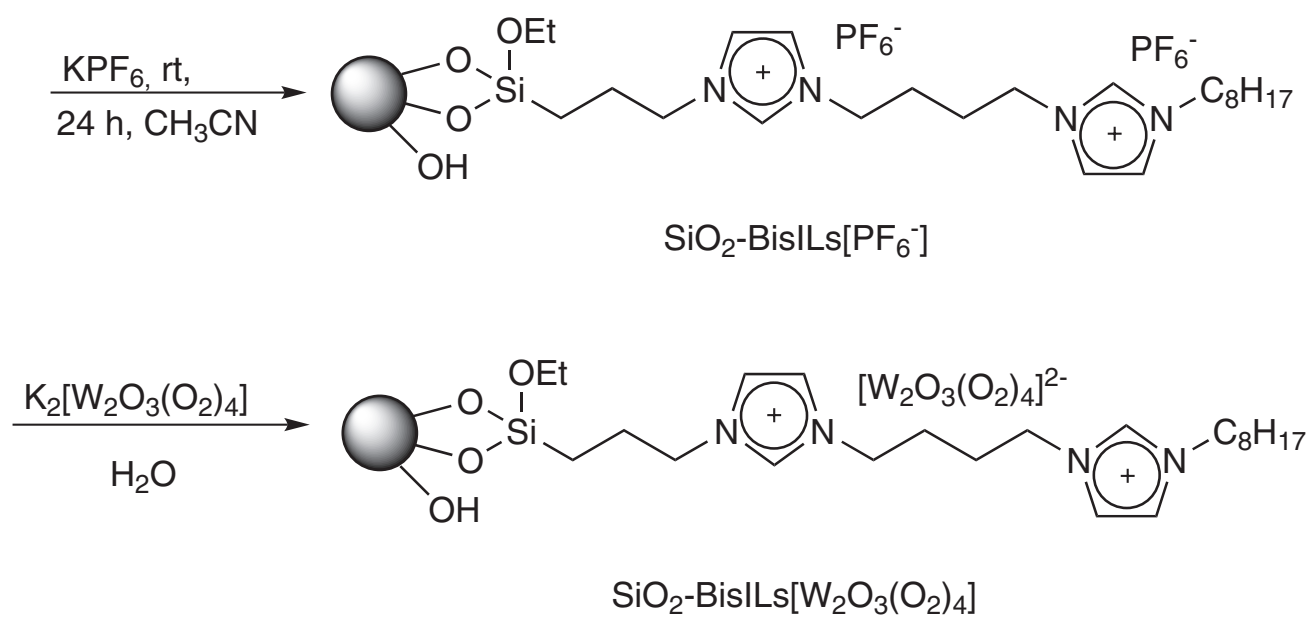

Scheme 1. Preparation of peroxotungstate-ionic liquid brush assembly.

conditions and the examination of the catalytic activity in neat water. All reactions were carried out by simply stirring a mixture of the catalyst, methyl phenyl sulfide, and $\mathrm{H}_{2} \mathrm{O}_{2}$ in neat water at room temperature, using different amounts of $\mathrm{H}_{2} \mathrm{O}_{2}$ and catalyst. No organic co-solvents or additives were employed. The results are listed in Table 1 (entries 1-9).

It can be seen from Table 1 that the brush catalyst is efficient for the oxidation of methyl phenyl sulfide with $\mathrm{H}_{2} \mathrm{O}_{2}$ in neat water. In sharp contrast, the control experiment (with no catalyst) led to a very low yield of $3.2 \%$ (entry 1 ). This demonstrated that the catalyst plays a critical role in the reaction. Meanwhile, using $\mathrm{SiO}_{2}-\mathrm{IL}[\mathrm{Cl}]$ and $\mathrm{SiO}_{2}-\mathrm{IL}\left[\mathrm{PF}_{6}^{-}\right]$as catalyst directly, the poor yields of methyl phenyl sulfoxide were obtained, which displayed that peroxotungstate is the effective catalytic center to active hydrogen peroxide. Moreover, the catalyst prepared by the chloride anion directly exchanged with peroxotungstate also gave lower yield of product, which showed that to synthesize high efficiency catalyst, the exchangement between $\mathrm{Cl}^{-}$and $\mathrm{PF}_{6}^{-}$is important and necessary. A catalyst:sulfide molar ratio of 1.5:100 is recommended. If the ratio of the catalyst is reduced to $1.0 \mathrm{~mol} \%$, levels of oxidation are significantly reduced (entry 2). A catalyst ratio of 2 mol\% also led to unsatisfactory yield (entry 5). These results may be rationalized by the over-oxidation of sulfoxide. In fact, the minimal sulfone was detected by GC (gas chromatography) as the over-oxidation product.
Moreover, the optimum molar ratio of sulfide and $\mathrm{H}_{2} \mathrm{O}_{2}$ is $1: 1.2$. Although the conversion of the sulfide improves with the increasing amount of the $\mathrm{H}_{2} \mathrm{O}_{2}$, the yield of the sulfoxide decreases owing to a reduced selectivity for the sulfoxide.

To explore the scope of our protocol for the selective oxidation of sulfides to sulfoxides, various functionalized sulfides were employed under the optimized conditions using the $\mathrm{SiO}_{2}$ - $\mathrm{BisILs}\left[\mathrm{W}_{2} \mathrm{O}_{3}\left(\mathrm{O}_{2}\right)_{4}\right]$ and $\mathrm{H}_{2} \mathrm{O}_{2}$ system. The results are summarized in Table 1 (entries 10-18). In most cases, aryl-alkyl, aryl-aryl, alkyl-alkyl sulfides were successfully oxidized to the corresponding sulfoxides in excellent yield and high selectivity. Only trace levels of their over-oxidation sulfone products were detected by GC. Similarly, the catalyst provided excellent chemoselectivity towards sulfides containing oxidation sensitive functional groups. More notably, allylic sulfides gave sulfoxides selectively in high yield with short reaction times, leaving the double bonds unaffected (entries 11, 12). This is important, since tungsten-based catalysts are well known to promote epoxidation reactions or carbon-carbon double bond cleavage hydrogen peroxide based processes. ${ }^{29-33}$ Hydroxyl groups also remained intact under these conditions (entry 16) and the corresponding sulfoxide was obtained in $93.9 \%$ of yield. The reaction times required for sulfoxide formation ranged from 1.5 to $4 \mathrm{~h}$ for all substrates except for diphenyl sulfide, which took $7 \mathrm{~h}$ and led to the lowest yield (entry 14). This may be due to the 
Table 1. The brush catalyzed on-water oxidation of sulfides to sulfoxides with $\mathrm{H}_{2} \mathrm{O}_{2}{ }^{\text {a }}$

\begin{tabular}{|c|c|c|c|c|c|c|c|}
\hline entry & $\mathrm{R}^{1}$ & $\mathrm{R}^{2}$ & catalyst (eq.) $)^{\mathrm{b}}$ & $\mathrm{H}_{2} \mathrm{O}_{2}$ (eq.) & time / h & Conversion $/ \% \mathrm{c}$ & Yield / \% \\
\hline 1 & $\mathrm{C}_{6} \mathrm{H}_{5}$ & $\mathrm{Me}$ & NO & 1.2 & 3 & 4 & 3 \\
\hline 2 & & & 0.010 & 1.2 & 3 & 88 & 85 \\
\hline 3 & & & 0.013 & 1.2 & 3 & 92 & 88 \\
\hline 4 & & & 0.018 & 1.2 & 3 & 94 & 91 \\
\hline 5 & & & 0.020 & 1.2 & 3 & 99 & 88 \\
\hline 6 & & & 0.015 & 1.1 & 3 & 91 & 90 \\
\hline 7 & & & 0.015 & 1.2 & 3 & 100 & 93 \\
\hline 8 & & & 0.015 & 1.3 & 3 & 100 & 90 \\
\hline 9 & & & 0.015 & 1.4 & 3 & 100 & 85 \\
\hline $10^{e}$ & & & 0.015 & 1.2 & 3 & 10 & 9 \\
\hline $11^{f}$ & & & 0.015 & 1.2 & 3 & 14 & 14 \\
\hline $12^{s}$ & & & 0.015 & 1.2 & 3 & 69 & 55 \\
\hline 13 & $n$-butyl & $n$-butyl & 0.015 & 1.2 & 3 & 87 & 84 \\
\hline 14 & allyl & allyl & 0.015 & 1.2 & 1.5 & 100 & 87 \\
\hline 15 & allyl & $\mathrm{Me}$ & 0.015 & 1.2 & 2 & 93 & 91 \\
\hline 16 & $p-\mathrm{NO}_{2} \mathrm{C}_{6} \mathrm{H}_{4}$ & $\mathrm{Me}$ & 0.015 & 1.2 & 4 & 92 & 92 \\
\hline 17 & $\mathrm{C}_{6} \mathrm{H}_{5}$ & $\mathrm{C}_{6} \mathrm{H}_{5}$ & 0.015 & 1.2 & 7 & 76 & 71 \\
\hline 18 & $\mathrm{ClCH}_{2} \mathrm{CH}_{2}$ & Et & 0.015 & 1.2 & 2 & 96 & 94 \\
\hline 19 & $\mathrm{HOCH}_{2} \mathrm{CH}_{2}$ & Et & 0.015 & 1.2 & 4 & 99 & 94 \\
\hline 20 & $p-\mathrm{BrC}_{6} \mathrm{H}_{4}$ & $\mathrm{Me}$ & 0.015 & 1.2 & 3.5 & 84 & 76 \\
\hline 21 & & $\mathrm{Me}$ & 0.015 & 1.2 & 3.5 & 93 & 90 \\
\hline
\end{tabular}

aConditions: sulfides $(5 \mathrm{mmol}), \mathrm{H}_{2} \mathrm{O}(5 \mathrm{~mL})$, were stirred at room temperature; based on the content of tungsten; ${ }^{\mathrm{c}}$ determined by $\mathrm{GC}$; ${ }^{\text {issolated yields }(\text { average }}$ in two runs); ${ }^{\mathrm{e}} \mathrm{use} \mathrm{SiO}_{2}-\mathrm{BisILs}[\mathrm{Cl}]$ as catalyst; ${ }^{\mathrm{f}} \mathrm{use} \mathrm{SiO}_{2}-\mathrm{BisILs}\left[\mathrm{PF}_{6}{ }^{-}\right]$as catalyst; ${ }^{\mathrm{g}}$ the catalyst was prepared by the chloride anion exchanged directly with peroxotungstate.

steric influence of phenyl ring. Moreover, the presence of electron withdrawing substituents on the phenyl ring required slightly longer reaction time compared with methyl phenyl sulfoxide (entry 13).

By simply increasing the amount of $\mathrm{H}_{2} \mathrm{O}_{2}$, the sulfides can be selectively oxidized to sulfones. Methyl phenyl sulfide was again chosen as model substrate for reaction optimization (Table 2, entries 1-8). The results show that the most suitable molar ratio of the catalyst, sulfide and $\mathrm{H}_{2} \mathrm{O}_{2}$ is 1.5:100:280 (entry 5). To explore the scope and the limitations of our catalyst, the oxidation of a variety of sulfides was investigated with the optimized reaction conditions (Table 2, entries 9-18). The catalyst works well for all substrates. All reactions resulted in $100 \%$ sulfide conversion and all sulfone yields exceeded $85 \%$. Even with the highly hindered diphenyl sulfide, the oxidation afforded diphenyl sulfone in $94.3 \%$ yield with a prolonged reaction time of $18 \mathrm{~h}$ (entry 13). Similar to the oxidation of sulfides to sulfoxides, functional group tolerance was excellent, even when hydrogen peroxide was used in great excess. Substrates containing sensitive functional groups such as alkenes and alcohols (entries 10, 11 and 16) were selectively oxidized at the sulfur atom. These results further exemplify the catalytic oxidation system excellent chemoselectivity.

Convenient recyclability and a prolonged retention of catalytic activity are two very important features for the practical and efficient application of catalytic processes. The reusability of our catalyst was established by carrying out the repeated oxidation of methyl phenyl sulfide, with each successive catalyst recovery, under the optimum conditions. It is particularly worthy to point out that the 
Table 2. The brush catalyzed on-water oxidation of sulfides to sulfones with $\mathrm{H}_{2} \mathrm{O}_{2}{ }^{\text {a }}$

\begin{tabular}{|c|c|c|c|c|c|c|}
\hline entry & $\mathrm{R}^{1}$ & $\mathrm{R}^{2}$ & Catalyst (eq.) $^{\mathrm{b}}$ & $\mathrm{H}_{2} \mathrm{O}_{2}$ (eq.) & time / h & Yield / \% \\
\hline 1 & $\mathrm{C}_{6} \mathrm{H}_{5}$ & $\mathrm{Me}$ & 0.02 & 2.0 & 9 & 58 \\
\hline 2 & & & 0.02 & 2.2 & 9 & 63 \\
\hline 3 & & & 0.02 & 2.4 & 9 & 64 \\
\hline 4 & & & 0.02 & 2.6 & 9 & 70 \\
\hline 5 & & & 0.02 & 2.8 & 9 & 98 \\
\hline 6 & & & 0.02 & 3.0 & 9 & 96 \\
\hline 7 & & & 0.15 & 2.8 & 9 & 89 \\
\hline 8 & & & 0.25 & 2.8 & 9 & 97 \\
\hline 9 & $n$-butyl & $n$-butyl & 0.02 & 2.8 & 9 & 98 \\
\hline 10 & allyl & allyl & 0.02 & 2.8 & 9 & 100 \\
\hline 11 & allyl & $\mathrm{Me}$ & 0.02 & 2.8 & 9 & 99 \\
\hline 12 & $p-\mathrm{NO}_{2} \mathrm{C}_{6} \mathrm{H}_{4}$ & $\mathrm{Me}$ & 0.02 & 2.8 & 11 & 99 \\
\hline 13 & $\mathrm{C}_{6} \mathrm{H}_{5}$ & $\mathrm{C}_{6} \mathrm{H}_{5}$ & 0.02 & 2.8 & 18 & 94 \\
\hline 14 & Et & $\mathrm{Me}$ & 0.02 & 2.8 & 7 & 100 \\
\hline 15 & $\mathrm{ClCH}_{2} \mathrm{CH}_{2}$ & Et & 0.02 & 2.8 & 13 & 86 \\
\hline 16 & $\mathrm{HOCH}_{2} \mathrm{CH}_{2}$ & Et & 0.02 & 2.8 & 13.5 & 94 \\
\hline 17 & $p-\mathrm{BrC}_{6} \mathrm{H}_{4}$ & $\mathrm{Me}$ & 0.02 & 2.8 & 24 & 93 \\
\hline 18 & & $\mathrm{Me}$ & 0.02 & 2.8 & 16 & 95 \\
\hline
\end{tabular}

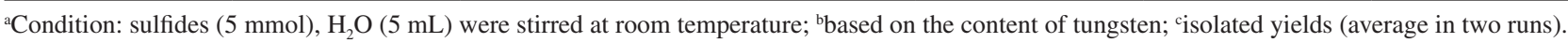

Table 3. The recycling of catalyst in the selective oxidation of methyl phenyl sulfide ${ }^{a}$

\begin{tabular}{lcccccccc}
\hline Cycle & 1 & 2 & 3 & 4 & 5 & 6 & 7 & 8 \\
\hline Yield $/ \%^{\mathrm{b}}$ & 93 & 92 & 91 & 92 & 92 & 91 & 90 & 89 \\
\hline
\end{tabular}

${ }^{a}$ Condition: methyl phenyl sulfide $(5 \mathrm{mmol}), \mathrm{H}_{2} \mathrm{O}_{2}(6 \mathrm{mmol}), \mathrm{H}_{2} \mathrm{O}(5 \mathrm{~mL})$ and catalyst $(0.075 \mathrm{mmol}$, based on the content of tungsten $)$ were stirred at room temperature for $3 \mathrm{~h}$; bisolated yields (average in two runs).

use of water as solvent allows easy recycling of the catalyst since the catalyst can be recovered by a simple filtration. After the first use, the catalyst was filtered, washed with EtOAc and dried under vacuum before reuse. The recovered catalyst is then applied in the next cycle. Eight consecutive preparations of the methyl phenyl sulfoxide led to no significant loss in yields (Table 3), meaning the catalytic activity of the catalyst did not significantly change, as compared with fresh catalyst.

As expected, no significant leaching of metal was observed. ICP-MS (inductively coupled plasma mass spectrometry) analysis showed that after filtration of the catalyst the reaction stream contained only $0.50 \mathrm{mg} \mathrm{L}^{-1}$ of W. This result makes this catalytic system possess great significance in the synthesis of sulfoxide or sulfone drugs, in which the content of heavy metal is strictly limited.

\section{Conclusions}

In summary, a "real" on-water procedure and an environmentally benign catalyst for the synthesis of sulfoxides and sulfones, with a 30 wt.\% aqueous $\mathrm{H}_{2} \mathrm{O}_{2}$ solution at room temperature, was developed. It avoids the use of any organic co-solvent or addictive. Sulfides were easily and selectively converted to sulfoxides or sulfones in high yield by simply controlling the equivalents of hydrogen peroxide. The catalyst combines the advantage of ionic liquids and peroxotungstate, and differentiates 
itself from other peroxotungstate-based catalysts with its high efficiency, simple isolation of product and catalyst, outstanding recyclability and organic solvent-free conditions. Our group believes that this oxidation system will find applications in both academic and industrial laboratories.

\section{Experimental}

\section{General}

Unless otherwise stated, all reagents were purchased from commercial sources and used without purification. Reaction progress was monitored by TLC (thin layer chromatography) using Merck silica gel 60 F-254 with detection by UV or concentrated sulfuric acid as chromogenic reagent. Flash chromatography was performed with freshly distilled solvents. Columns were typically packed as slurry and equilibrated with the appropriate solvent system prior to use. ICP-MS was measured by $\mathrm{X}$ series $\Pi$ mass spectrometer. ${ }^{1} \mathrm{H}$ and ${ }^{13} \mathrm{C}$ MNR (nuclear magnetic resonance) spectra were recorded on a Bruker AVANCE300 MHz spectrometer (tetramethylsilane (TMS) as an internal standard). GC analysis was performed on an Agilent $6890 \mathrm{~N}$ using a capillary column (HP-5, $30 \mathrm{~m} \times 0.25 \mathrm{~mm} \times 0.53 \mu \mathrm{m})$ with a flame ionization detector (FID).

\section{Synthesis of catalyst}

The ionic liquid brushes $\mathrm{SiO}_{2}$-BisILs[Cl] was synthesized via a 3 -step route according to the procedure that our group previously reported. ${ }^{27}$ The exchange between $\mathrm{Cl}^{-}$and $\mathrm{PF}_{6}^{-}$was performed by the direct reaction of the $\mathrm{SiO}_{2}$-BisILs $[\mathrm{Cl}]$ and $\mathrm{KPF}_{6}$ in $\mathrm{CH}_{3} \mathrm{CN}$ at room temperature for $24 \mathrm{~h}$. After the reaction, the obtained material was washed consecutively with water and acetone, then, dried under vacuum at $70{ }^{\circ} \mathrm{C}$ over night. The bis-layered ionic liquid modified $\mathrm{SiO}_{2}$ was obtained. Elemental analysis: found $\mathrm{C} 12.48 \%, \mathrm{H} 1.80 \%, \mathrm{~N} 2.96 \%$; IR ( $\mathrm{KBr}$ disk) $v_{\text {max }} / \mathrm{cm}^{-1} 3162,2938$ and $2860 v(\mathrm{C}-\mathrm{H}), 1636 \mathrm{~cm}^{-1}, v(\mathrm{C}=\mathrm{N})$, $832 \mathrm{v}\left(\mathrm{PF}_{6}^{-}\right)$; specific surface area $\left(\mathrm{S}_{\mathrm{BET}}\right)$ of $117 \mathrm{~m}^{2} \mathrm{~g}^{-1}$.

The ionic liquid brushes $\mathrm{SiO}_{2}$-BisILs $\left[\mathrm{PF}_{6}\right](1 \mathrm{~g})$ was suspended in a solution of $\mathrm{K}_{2}\left[\mathrm{~W}_{2} \mathrm{O}_{3}\left(\mathrm{O}_{2}\right)_{4}\right] \cdot 2 \mathrm{H}_{2} \mathrm{O}(1.316 \mathrm{~g}$, $2 \mathrm{mmol})$ in water $(20 \mathrm{~mL})$, and the mixture was stirred at room temperature for $24 \mathrm{~h}$. After filtration and dry in vacuo, the catalyst of peroxotungstate-ionic liquid brush assembly was prepared according to the previous reference. ${ }^{34}$ Elemental analysis: found C $12.06 \%, \mathrm{H} 1.71 \%$, N 2.64\%, IR (KBr disk) $v_{\text {max }} / \mathrm{cm}^{-1} 3166,2937$ and 2864 $v(\mathrm{C}-\mathrm{H}), 1638 v(\mathrm{C}=\mathrm{N}), 831 v\left(\mathrm{PF}_{6}^{-}\right), 935 \mathrm{v}(\mathrm{W}=\mathrm{O}), 844$
$v(\mathrm{O}-\mathrm{O}), 731 \mathrm{v}\left(\mathrm{W}_{2} \mathrm{O}\right), 560 \mathrm{v}\left(\mathrm{W}\left(\mathrm{O}_{2}\right)\right)$; specific surface area $\left(S_{\mathrm{BET}}\right)$ of $103 \mathrm{~m}^{2} \mathrm{~g}^{-1}$. The loading amount of tungsten was $0.334 \mathrm{mmol} \mathrm{g}^{-1}$.

General procedure for the selective oxidation of sulfides to sulfoxides

In a typical experimental procedure, to a $25 \mathrm{~mL}$ flask, the mixture of catalyst (1.5 mol\% with respect to substrate) and $5 \mathrm{~mL}$ water was stirred at room temperature for about $10 \mathrm{~min}$. Then, sulfide $(5 \mathrm{mmol})$ and $30 \mathrm{wt} . \%$ aq. $\mathrm{H}_{2} \mathrm{O}_{2}$ (6 mmol) were successively added. The resulting mixture was electromagnetically stirred at room temperature and monitored by TLC. After the completion of the reaction, the catalyst was separated by filtration under reduced pressure, washed with EtOAc $(3 \times 5 \mathrm{~mL})$, and dried in vacuum. The combined organic layer was dried with anhydrous $\mathrm{MgSO}_{4}$, and concentrated under reduced pressure to give the crude product which was purified by silica gel column chromatography using petroleum ether-EtOAc as eluent. The products were confirmed by ${ }^{1} \mathrm{H}$ NMR.

General procedure for the selective oxidation of sulfides to sulfones

The methods of oxidizing sulfides to sulfones were similar to that of sulfoxides except that the ratio of catalyst, $\mathrm{H}_{2} \mathrm{O}_{2}$, and sulfide was changed from 1.5:120:100 to 2:280:100. The products were confirmed by ${ }^{1} \mathrm{H}$ NMR.

Reusability of the catalyst

The selective oxidation of methyl phenyl sulfide to sulfoxide as a model reaction was carried out under the optimum conditions to examine the recyclability of the catalyst. After completion of the reaction in the first run, the catalyst was separated by filtration under reduced pressure, washed with EtOAc $(3 \times 5 \mathrm{~mL})$. After complete drying, the catalyst was charged again into the vessel containing water, the post-processing was the same as above and the reaction was performed under the same conditions.

\section{Supplementary Information}

Supplementary information (Figures S1-S21) is available free of charge at http://jbcs.sbq.org.br as PDF file.

\section{Acknowledgements}

The authors are grateful to the National Foundation of Natural Science (Grant No. 20906059 and 21072123), the 
Fundamental Research Funds for the Central Universities (Grant GK201102005), the Foundation of Science and Technology Planning Project of Xi' an City (Grant No.CXY1121) and the Innovation Foundation of Graduate Cultivation of Shaanxi Normal University (Grant No. 2012CXS041) for providing financial support for this research.

\section{References}

1. Fernandez, I.; Khiar, N.; Chem. Rev. 2003, 103, 3651.

2. Kowalski, P.; Mitka, K.; Ossowska, K.; Kolarska, Z.; Tetrahedron 2005, 61, 1933.

3. Dorta, R.; Shimon, L. J. W.; Milstein, D.; Chem. Eur. J. 2003, 9, 5237.

4. Lee, H. B.; Ren, T.; Inorg. Chim. Acta 2009, 362, 1467.

5. Maayan, G.; Popovitz-Biro, R.; Neumann, R.; J. Am. Chem. Soc. 2006, 128, 4968.

6. Cojoariu, A. M.; Mutin, P. H.; Dumitriu, E.; Fajula, F.; Viouxa, A.; Hulea, V.; Chem. Commun. 2008, 5357.

7. Sreedhar, B.; Radhika, P.; Neelima, B.; Hebalkar, N.; Mishra, A. K.; Catal. Commun. 2008, 10, 39.

8. Da Costa, A. P.; Reis, P. M.; Gamelas, C.; Romão, C. C.; Royo, B.; Inorg. Chim. Acta 2008, 361, 1915.

9. Bharadwaj, S. K.; Hussain, S.; Kar, M.; Chaudhuri, M. K.; Catal. Commun. 2008, 9, 919.

10. Chen, Y. J.; Shen, J. Y.; Tetrahedron Lett. 2005, 46, 4205.

11. Mirkhani, V.; Moghadam, M.; Tangestaninejad, S.; Mohammdpoor-Baltork, I.; Kargar, H.; Araghi, M.; Appl. Catal., A 2009, 353, 61.

12. Al-Hashimi, M.; Roy, G.; Sullivan, A. C.; Wilson, J. R. H.; Tetrahedron Lett. 2005, 46, 4365.

13. Salgaonkar, P. D.; Shukla, V. G.; Akamanchi, K. G.; Synth. Commun. 2005, 35, 2805.

14. Huang, J. Y.; Li, S. J.; Wang, Y. G.; Tetrahedron Lett. 2006, 47, 5637.

15. Cojocariu,A. M.; Mutinc, P. H.; Dumitriu, E.; Fajula, F.; Vioux,A.; Hule, V.; Appl. Catal., B 2010, 97, 407.
16. Giuseppe, A. D.; Crucianelli, M.; Angelis, F. D.; Crestini, C.; Saladino, R.; Appl. Catal., B 2009, 89, 239.

17. Liu, P.; Wang, C. H.; Li, C.; J. Catal. 2009, 262, 159.

18. Saisaha, P.; Pijper, D.; van Summeren, R. P.; Hoen, R.; Smit, C.; de Boer, J. W.; Hage, R.; Alsters, P. L.; Feringaa, B. L.; Browne, W. R.; Org. Biomol. Chem. 2010, 8, 4444.

19. Liu, F. L.; Fu, Z. H.; Liu, Y. H.; Lu, C. L.; Wu, Y. Y.; Xie, F.; Ye, Z. P.; Zhou, X. P.; Yin, D. L.; Ind. Eng. Chem. Res. 2010, 49, 2533.

20. Hida, T.; Nogusa, H.; Tetrahedron 2009, 6, 270.

21. Zhao, W.; Zhang, Y. S.; Ma, B. C.; Ding, Y.; Qiu, W. Y.; Catal. Commun. 2010, 11, 527.

22. Shi, X. Y.; Wei, J. F.; J. Mol. Catal. A: Chem. 2008, 280, 142.

23. Narayan, S.; Muldoon, J.; Finn, M. G.; Fokin, V. V.; Kolb, H. C.; Sharpless, K. B.; Angew. Chem., Int. Ed. 2005, 44, 3275.

24. Li, C. J.; Chem. Rev. 2005, 105, 3095.

25. Chanda, A.; Fokin, V. V.; Chem. Rev. 2009, 109, 725.

26. Sheldon, R. A.; Green Chem. 2005, 7, 267.

27. Wei, J. F.; Jiao, J.; Feng, J. J.; Lv, J.; Zhang, X. R.; Shi, X. Y.; Chen, Z. G.; J. Org. Chem. 2009, 74, 6283.

28. Li, J.; Cao, J. J.; Wei, J. F.; Shi, X. Y.; Zhang, L. H.; Feng, J. J.; Chen, Z. G.; Eur. J. Org. Chem. 2011, 229.

29. Kasai, J.; Nakagawa, Y.; Uchida, S.; Yamaguchi, K.; Mizuno, N.; Chem. Eur. J. 2006, 12, 4176.

30. Al-Ajlouni, A. M.; Sağlam, Ö.; Diafla, T.; Kühn, F.; J. Mol. Catal. A: Chem. 2008, 287, 159.

31. Blach, P.; Böstrom, Z.; Franceschi-Messant, S.; Lattes, A.; Perez, E.; Rico-Lattes, I.; Tetrahedron 2010, 66, 7124.

32. Sato, K.; Aoki, M.; Noyori, R. A.; Science 1998, 281, 1646.

33. Antonelli, E.; D’Aloisio, R.; Gambaro, M.; Venturello, C.; J. Org. Chem. 1998, 63, 7190.

34. Cambell, N. J.; Dengel, A. C.; Edwards, C. J.; Griffith, W. P. J. Chem. Soc., Dalton Trans. 1989, 1203.

Submitted: December 19, 2011

Published online: July 31, 2012 